\title{
TOXICITY EFFECT OF EXPIRED PESTICIDES TO FRESHWATER FISH, Labeo rohita
}

\author{
G. Satyavani MSc ${ }^{*}$, R.A. Gopi $\mathrm{MSC}^{2}$, S. Ayyappan $\mathrm{PhD}^{3}$, P. Balakrishnamurthy $\mathrm{DSC}^{4}$ and P. \\ Neelakanta Reddy $\mathrm{PhD}^{5}$
}

\begin{abstract}
We selected 15 widely used pesticide formulations to investigate possible chemical, biological and toxicological effects of expired pesticides that may enter into our ecosystem. They comprised of organophosphate and pyrethroid based insecticides, azole based fungicides, acetamide, propionate, acetic acid based herbicides, and fungicides mixtures containing two actives of azole and dithiocarbamates. The selected compounds were tested for acute toxicity to fish, Labeo rohita using Organisation for Economic Co-operation and Development (OECD) guideline no. 203 under static condition. Five to six concentrations (ranges from $0.005-80 \mathrm{mg} / \mathrm{L}$ ) of both expired and unexpired pesticide formulations were tested along with controls under similar conditions at Department of Ecotoxicology, International Institute of Biotechnology and Toxicology. The results of the $L C_{50}$ (Lethal Concentration)demonstrated significantly lower $L C_{50}$ values for the expired pesticides as compared to the corresponding unexpired counter part. From this data, it is clear that expired pesticide formulations must be disposed carefully and, care should be taken to avoid their discharge to water bodies and thus prevent loss to fish.
\end{abstract}

Keywords: Fish toxicity, freshwater, Labeo rohita, pesticides

\section{INTRODUCTION}

The United Nations Food and Agriculture Organization (FAO) define obsolete pesticides as stocked pesticides that can no longer be used for their original purpose or any other purpose and therefore require disposal (FAO, 1995). FAO estimate that half a million tonnes of obsolete pesticides are in storage world-wide (Shah and Devkota, 2009). A broad definition of obsolete pesticides includes all pesticides - technical and formulations - past their expiry date ( 2 years post manufacture date), all banned pesticides, damaged and degraded products, unusable formulations and packages, unidentified products, associated contaminated empty containers and old application equipment, other contaminated materials and equipment, buried pesticides and containers and heavily contaminated soils (Mwandia and Touni, 2006). In developing economies, expired pesticides may enter into water bodies due to usage of expired pesticides, purchased due to lack of knowledge about expiry and due to malpractices in trading.

Expired pesticides, if present in ecosystem, may pose new issues of toxicological concern, which are not similar with unexpired product. Data and information are scanty on the possible altered toxicological effects and since considerable amount of expired pesticides do exist in our society, there is need to characterize the risk of such products. India has at least 200 tonnes of obsolete pesticides (Jayashree, 2010). According to some reported inventories and surveys, the quantity of expired pesticides is estimated above 5000 tons in North West Frontier Province, Pakistan (Khwaja et.al., 2006). A survey indicated that around 1000 tonnes of obsolete pesticides may be remained in Punjab (OECD-FAO-UNEP, 2000).

In some situations, it was observed that the dealers gave those pesticides to farmers, which were reportedly expired. The Pesticide Dealers trapped most of the farmers who had

1 Scientist, Int. Inst. of Biotech and Toxicology (IIBAT)-TamilNadu, India, satyavani1984@gmail.com

2 Scientist, Int. Inst. of Biotech and Toxicology (IIBAT)-TamilNadu, India, friends.gopi@gmail.com

3 S. scientist, Int. Inst. of Biotech and Toxicology (IIBAT)-TamilNadu, India, ayyaayaps@yahoo.com

4 Director, Int. Inst. of Biotech and Toxicology (IIBAT)-TamilNadu, India, director@iibat.com

5 Res.Supervisor, Cen. Leather Res. Inst. (CLRI)-TamilNadu, India, neelakantareddyp@gmail.com 
insufficient knowledge about selection of proper pesticides and no money to buy them. They bought pesticides on credit (Khooharo, 2008). Unfortunately, farmers may not be aware of the source of the pesticides sold to them and unwittingly introduce dangerous chemicals into the environment (Kreisler and Heiss, 2008). When croplands are treated, some impacts of pesticides occur on non-target terrestrial and aquatic ecosystems, as well as on adjoining agro ecosystems (Surendra, 2010). Surface water also can be contaminated directly by pesticide spray drift the travel and deposition of fine pesticide spray droplets away from their intended target when the spray is applied too close to water. Drift incidents can result in greater surface water contamination than either runoff or leaching. Obvious, acute effects such as fish kills can occur (Don et al., 1994). As pesticides degrade, they may leach into soil and water, or they may be windswept or volatilized reaching neighboring, or far away, areas (Kreisler and Heiss, 2008). Women who eat lots of fish from contaminated waters have been shown to have babies with elevated rates of mental, developmental, and behavioral disorders (Ram, 2002). The effects on fish occurred largely during the reproductive cycle (i.e., at the time that the yolk sac was absorbed) (Burdick et al., 1967). Some farmers reportedly underestimated the toxicity of the pesticides and thought that throwing of leftover pesticides in running water was their safe disposal. The only option to dispose of the expired pesticides was to bury them in fields (Incineration) (Khooharo, 2008). In the majority of cases, disposal of obsolete pesticides in developing countries entails repackaging, transportation to Europe and incineration in dedicated high temperature toxic waste incinerators. It costs about US\$3,000-US\$4,000 per tonne of waste. Other destruction options include incineration in local cement kilns, mobile incinerators, burial and low technology chemical treatments. They also need high levels of training, sophisticated equipment and long term maintenance, which are often inappropriate in developing countries (PAN UK, 1998).

Environment Impact Quotient calculated by Researchers at Cornell University by combining information on dermal toxicity, chronic toxicity, systemicity, fish toxicity, leaching potential, surface-loss potential, bird toxicity, soil half-life, bee toxicity, beneficial arthropod toxicity and plant surface half-life for individual pesticides. Calculations revealed a significant relative toxicity of many active ingredients stored in each stockpile for fish (Blankespoor et al., 2009). Hence, we focused on toxicity effects of expired pesticides on fish.

Labeo rohita is a prime cultured and important staple freshwater fish generally found in rivers, ponds, and reservoirs (Dube and Hosetti, 2010) and popular in Thailand, Bangladesh, northern India and Pakistan (Rainer et al., 2005). Hence, we investigated the effect of certain expired pesticides to Labeo rohita in acute exposure test.

The objective of this investigation was to evaluate the toxicity effect of expired pesticide formulations to freshwater fish, Labeo rohita using a standard test guidelines OECD \# 203 and Gaitonde Committee Guidelines (6.4.0.D.ii) to determine 96 hour LC $_{50}$ and NOEC (No observed Effect Concentration).

\section{MATERIALS AND METHODS}

The test pesticides and chemicals were selected based on their wide use in India (or elsewhere). Fifteen different pesticide products in combination under five groups of pesticides were assay studied (Table 1).

The above products were purchased from market and they were all in within the mandatory 2 years shelf life. The same 15 products as obtained from IIBAT's repository, but were expired (expiry ranged between 10 months to 24 months after the 2 year shelf life) were tested simultaneously as given in Table-1. Manufacturer's names and brand names are withheld. 
Table 1: Details of pesticide formulations used in the present study

\begin{tabular}{|c|c|c|c|}
\hline Test substance name & $\begin{array}{l}\text { Concentrations } \\
\text { exposed (mg/L) }\end{array}$ & $\begin{array}{l}\text { Date of } \\
\text { Manufacture }\end{array}$ & $\begin{array}{l}\text { Date of } \\
\text { Expiry }\end{array}$ \\
\hline \multicolumn{4}{|l|}{ Insecticides } \\
\hline Dichlorvos 76\% EC (Fresh) & \multirow{2}{*}{$\begin{array}{l}0.63,1.25,2.5, \quad 5 \\
\text { and } 10 \mathrm{mg} / \mathrm{L}\end{array}$} & Apr, 2010 & Apr, 2012 \\
\hline Dichlorvos 76\% EC (Expired) & & Nov, 2007 & Nov, 2009 \\
\hline Endosulfan 35\% EC (Fresh) & \multirow{2}{*}{$\begin{array}{l}0.5,1,2,4 \text { and } 8 \\
\mathrm{mg} / \mathrm{L}\end{array}$} & Mar, 2009 & Mar, 2011 \\
\hline Endosulfan 35\% EC (Expired) & & Aug, 2007 & Aug, 2009 \\
\hline Quinalphos 25\% EC (Fresh) & \multirow{2}{*}{$\begin{array}{l}0.3,0.6,1.3,2.5,5 \\
\text { and } 10 \mathrm{mg} / \mathrm{L}\end{array}$} & Nov, 2009 & Nov, 2011 \\
\hline Quinalphos 25\% EC (Expired) & & Aug, 2007 & Feb, 2009 \\
\hline \multicolumn{4}{|l|}{ Pyrethroids } \\
\hline Alphacypermethrin 10\% SC (Fresh) & \multirow{2}{*}{$\begin{array}{l}0.025, \quad 0.05, \\
0.2, \quad 0.4 \text { and } \\
\mathrm{mg} / \mathrm{L}\end{array}$} & Nov, 2009 & Nov, 2011 \\
\hline Alphacypermethrin 10\% SC (Expired) & & May, 2007 & Apr, 2009 \\
\hline Fenvalerate 20\% EC (Fresh) & \multirow{2}{*}{$\begin{array}{l}0.01, \quad 0.02, \quad 0.04 \\
0.08 \text { and } 0.16 \mathrm{mg} / \mathrm{L}\end{array}$} & Apr, 2009 & Apr, 2011 \\
\hline Fenvalerate 20\% EC (Expired) & & Sep, 2007 & Aug, 2009 \\
\hline Lambda-cyhalothrin 5\% EC (Fresh) & \multirow{2}{*}{$\begin{array}{l}0.005, \quad 0.01, \quad 0.02 \\
0.04 \text { and } 0.08 \mathrm{mg} / \mathrm{L}\end{array}$} & Jul, 2008 & Jul, 2010 \\
\hline Lambda-cyhalothrin 5\% EC (Expired) & & Jul, 2007 & Jul, 2009 \\
\hline \multicolumn{4}{|l|}{ Herbicides } \\
\hline Fenaxaprop-p-ethyl 9.3\% EC (Fresh) & \multirow{2}{*}{$\begin{array}{l}1.25,2.5,5,10 \text { and } \\
20 \mathrm{mg} / \mathrm{L}\end{array}$} & Jul, 2009 & Jun, 2011 \\
\hline Fenaxaprop-p-ethyl 9.3\% EC (Expired) & & Aug, 2007 & Jul, 2009 \\
\hline Pretilachlor 50\% EC(Fresh) & \multirow{2}{*}{$\begin{array}{l}1,2,4,8 \text { and } 16 \\
\mathrm{mg} / \mathrm{L}\end{array}$} & Nov, 2009 & Nov, 2011 \\
\hline Pretilachlor 50\% EC (Expired) & & Aug, 2007 & Aug, 2009 \\
\hline 2, 4 D sodium salt 80\% WP (Fresh) & \multirow{2}{*}{$100 \mathrm{mg} / \mathrm{L}$} & Aug, 2009 & Aug, 2011 \\
\hline 2, $4 \mathrm{D}$ sodium salt $80 \%$ WP (Expired) & & Aug, 2007 & Aug, 2009 \\
\hline \multicolumn{4}{|l|}{ Fungicides } \\
\hline Tebuconazole 25\% EC (Fresh) & \multirow{2}{*}{$\begin{array}{l}3.13,6.25,12.5,25 \\
\text { and } 50 \mathrm{mg} / \mathrm{L}\end{array}$} & May, 2007 & May, 2010 \\
\hline Tebuconazole 25\% EC (Expired) & & May, 2007 & May, 2009 \\
\hline Mancozeb 75\% WP (Fresh) & \multirow{2}{*}{$\begin{array}{l}2,4,8,16,32 \text { and } \\
64 \mathrm{mg} / \mathrm{L}\end{array}$} & Dec, 2008 & Dec, 2010 \\
\hline Mancozeb 75\% WP (Expired) & & Sep, 2007 & Sep, 2009 \\
\hline Hexaconazole 5\% EC (Fresh) & \multirow{2}{*}{$\begin{array}{l}2.5,5,10,20 \text { and } \\
40 \mathrm{mg} / \mathrm{L}\end{array}$} & Aug, 2008 & Jul, 2010 \\
\hline Hexaconazole 5\% EC (Expired) & & Nov, 2006 & Oct, 2008 \\
\hline \multicolumn{4}{|l|}{ Combinational Fungicides } \\
\hline Captan 70\% + Hexaconazole 5\% WP (Fresh) & \multirow{2}{*}{$\begin{array}{l}0.3,0.6,1.3,2.5,5 \\
\text { and } 10 \mathrm{mg} / \mathrm{L}\end{array}$} & Jul, 2009 & Jul, 2011 \\
\hline Captan 70\% + Hexaconazole 5\% WP (Expired) & & Feb, 2007 & Feb, 2009 \\
\hline Carbendazim 12\% + Mancozeb 63\% WP (Fresh) & \multirow{2}{*}{$\begin{array}{l}1,2,4,8 \text { and } 16 \\
\mathrm{mg} / \mathrm{L}\end{array}$} & Feb, 2010 & Feb, 2012 \\
\hline Carbendazim 12\% + Mancozeb 63\% WP (Expired) & & Apr, 2007 & Apr, 2009 \\
\hline Metalaxyl 8\% + Mancozeb 64\% WP (Fresh) & \multirow{2}{*}{$\begin{array}{l}5,10,20,40 \text { and } \\
80 \mathrm{mg} / \mathrm{L}\end{array}$} & Sep, 2009 & Sep, 2011 \\
\hline Metalaxyl 8\% + Mancozeb 64\% WP (Expired) & & Aug, 2006 & Aug, 2008 \\
\hline
\end{tabular}

Fish (Labeo rohita) used in this study were procured from commercial fish farm (Tamil Nadu Fish Seed Farm, Poondi, Thiruvallur dist., Tamil Nadu, India). The size of the fish was in the 
range of 5 to $7.5 \mathrm{~cm}$ and weight of fish was around $2 \mathrm{~g} /$ fish. Fish were acclimatized to the laboratory conditions for 7 days and fish were kept in starvation for 24 hour prior to the commencement of the study.

The acute toxicity study to the fresh water fish, Labeo rohita was conducted as per OECD 203 testing guidelines (OECD, 1992) and Gaitonde Committee Guidelines (6.4.0.D.ii).

The test room was maintained with 12 hours light and 12 hours darkness controlled by an automatic timer and test temperature was maintained between $21-25^{\circ} \mathrm{C}$. Glass aquaria $(25$ $\mathrm{L}$ capacity) were used as test Chamber. Exposure medium was blended water (well water and reverse osmosis water in the mixture of 1:1 ratio). $\mathrm{pH}$ of both expired and unexpired products was determined by making $1 \%$ solution using $\mathrm{pH}$ meter (Eutech $\mathrm{pH}$ Testr 30 ) at temperature $25^{\circ} \mathrm{C}$.

The study was performed with 5 groups of (fifteen) expired pesticides and fish were exposed to five to six test concentrations and blended water as a control for each test substance (Table 1). The test concentrations were fixed for each test substance based on reference literature (BCPC, 2003). The fish were exposed for 96hours. One test aquarium (contains $20 \mathrm{~L}$ of exposure medium) was used per test concentration for each test substance with ten fish in each chamber. Observations for mortality were made twice on the first day ( 3 hours and 6 hours) of the exposure, thereafter at the end of every 24 hours until 96 hours, when the experiment was terminated.

During the experiment, physico-chemical parameters $(\mathrm{pH}$, temperature, dissolved oxygen and hardness) were determined in the exposure medium for each test substance in control and highest concentrations at the start and end of the experiment. The $\mathrm{pH}$, temperature, conductivity and dissolved oxygen was analysed using instruments (Eutech pH Testr 30 and Lovibond-Sensodirect Oxi200) and total hardness (EDTA method) was determined following the methods given by APHA et al. (1975).

Mortality data of fish at the end of $96 \mathrm{~h}$ exposure were analysed using software- TOXSTAT 3.5 version (West Inc and Gulley, 1996) and $\mathrm{LC}_{50} \mathrm{~S}$ (with 95\% confidence limits), NOEC (Fisher's exact test) were derived.

\section{RESULTS AND DISCUSSIONS}

$\mathrm{LC}_{50}$ and NOEC values are given in Table 2. $\mathrm{LC}_{50}$ values of expired Fenvalerate $20 \% \mathrm{EC}$, Lambda cyhalothrin 5\% EC, Fenoxaprop p ethyl 9.3\% EC, Tebuconazole 25\% EC and Hexaconazole 5\% EC were lower to unexpired, meaning they are toxic as against to the unexpired. EC based expired formulations were more toxic as compared to other types of formulations -WP and SC, suggesting that organic solvent based formulations could be more toxic. The impurities may contribute to the toxicity of the pesticide or may alter the physical properties of the product (Ambrus et al., 2003). Pesticides have the property of bioaccumulation and biomagnifications and they will derive long lasting impacts on the environment and human health (Shah and Devkota, 2009). Data on pH of expired and unexpired formulations are given in Table 3. Some of the expired pesticides Dichlorvos $76 \%$ EC, Fenvalerate 20\% EC, Lambda-cyhalothrin 5\% EC, Pretilachlor 50\% EC, Tebuconazole $25 \%$ EC, Hexaconazole 5\% EC and Captan 70\% + Hexaconazole 5\% WP tested exhibited major change in $\mathrm{pH}$. Although when the study was performed the $\mathrm{pH}$ of the exposure medium did not differ, the decreased $\mathrm{LC}_{50}$ of expired pesticides could be due to degrading substance/s in them due to altered $\mathrm{pH}$, though the nature of these are not studied in this study. 


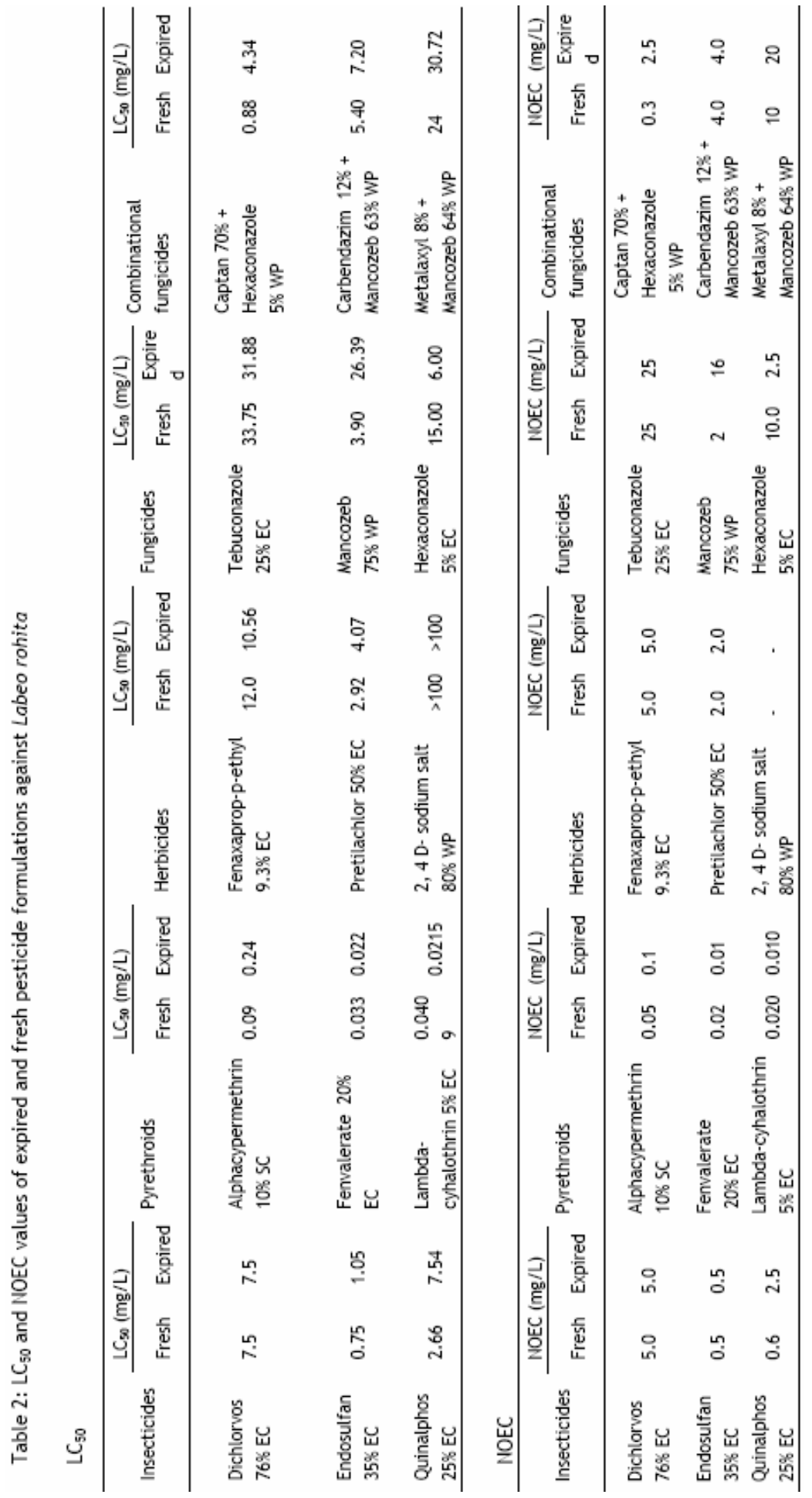


Table 3: $\mathrm{pH}$ of fresh and expired pesticide formulations (1\% solution)

\begin{tabular}{llll}
\hline S.No. & Test substance name & Fresh & Expired \\
\hline 1 & Dichlorvos 76\% EC & 2.56 & 1.56 \\
2 & Endosulfan 35\% EC & 5.66 & 5.79 \\
3 & Quinalphos 25\% EC & 6.31 & 6.43 \\
4 & Alphacypermethrin 10\% SC & 5.65 & 5.81 \\
5 & Fenvalerate 20\% EC & 4.85 & 6.65 \\
6 & Lambda-cyhalothrin 5\% EC & 4.79 & 6.29 \\
7 & Fenaxaprop-p-ethyl 9.3\% EC & 4.10 & 4.64 \\
8 & Pretilachlor 50\% EC & 6.68 & 4.72 \\
9 & 2, 4 D sodium salt 80\% WP & 8.75 & 8.73 \\
10 & Tebuconazole 25\% EC & 4.14 & 5.48 \\
11 & Mancozeb 75\% WP & 8.20 & 7.90 \\
12 & Hexaconazole 5\% EC & 4.45 & 3.98 \\
13 & Captan 70\% + Hexaconazole 5\% WP & 5.16 & 2.56 \\
14 & Carbendazim 12\% + Mancozeb 63\% WP & 8.13 & 8.07 \\
15 & Metalaxyl 8\% + Mancozeb 64\% WP & 7.91 & 8.12 \\
\hline
\end{tabular}

Fish and aquatic animals are exposed to pesticides in three primary ways (i) dermally, direct absorption through the skin by swimming in pesticide-contaminated waters, (ii) breathing, by direct uptake of pesticides through the gills during respiration, and (iii) orally, by drinking pesticide-contaminated water or feeding on pesticide contaminated prey (Mathur and singh, 2006). The continual contamination and pollution faced by the Nigerian Coastal and Marine environment from pesticides run-offs with resultant fish kills and human deaths (PAN Nigeria, 2007). Some soluble pesticides are easily leached into streams and lakes (David, 2005). A study was carried out from April 1999 to May 2000 to investigate the extent of pollution of Lake Nakuru with respect to organochlorine pesticide residues. The sampling periods included both dry and rainy seasons. Results revealed that more contaminants are added to the lake during rainy season than dry season (Mavura and Wangila, 2004). Fish kills occur when pesticides are improperly applied to or otherwise end up in bodies of water through either misapplication or drift (Mike, 2007). Accidental killing of fish due to the contamination of the aquatic environment remains among the most frequent poisoning cases. Every year, about 260 to 300 of such accidents are diagnosed (Helena and Zdenka, 2009).

Exposure to toxic substances may not result in immediate fish kills, but may affect fish populations by decreasing fecundity (number of eggs produced), reducing the viability of sperm, eggs and larvae, decreasing life expectancy, increasing the incidence of abnormalities and increasing natural mortality (Allan, 2000). Herbicides and insecticides used in agriculture have been responsible for a number of fish kills. Endosulphans used in the cotton growing areas have been particularly problematic over the last decade (Napier et al. 1998). Atrazine is one of the most widely used herbicides and considered as a common terrestrial and aquatic contaminant. Atrazine at low concentrations caused kidney damage in chronic exposed rainbow trout (Oulmi et al., 1995). The pesticide residues were found to cause impairment in reproductive system and thyroid activity in aquatic fauna, fish 
(Great and Mehrle, 1969). In a case in Mozambique, pesticides had been burned on a site which had subsequently been covered up with soil. Residues from the incineration had contaminated the surrounding soil, which local populations had discovered was toxic to fish, and had been used by local populations to catch fish in the local river. The toxic soil would cause fish to die instantly, floating up to the surface, where they would be caught and consumed or sold on the local market (FAO and DINA, 2004). High DDT and dieldrin residues were reported in African fish at levels that could potentially affect their reproduction have chronic toxic and behavioral effects and even drastically affect their population (Paul, 2005). So far there is no fish toxicity data available for expired pesticides.

However, expired drugs and pharmaceuticals release in water lead to biological change in fish which leads to reproductive defects. Like agrochemicals, Pharmaceuticals and Personal Care Products (PPCPs) are disposed or discharged into the environment on a continual basis via industrial and household sewage and waste (many individuals dispose of unwanted and expired drugs directly into the domestic sewage system or garbage) (Kreisberg, 2007). They may not cause acute toxicity in aquatic organisms, they may interfere with endocrine systems, particularly when exposure occurs during sensitive times of development such as before birth (SCBWMI, 2005). Studies have found fish in contaminated water with reproductive defects as well as alarmingly high ratios of female to male fish in some locations (KCT, 2009). Dangers of flushing toxic chemicals into the ecosystem through municipal sewer systems, one potentially devastating threat to wild fish populations comes from an unlikely source, estrogen. Male fish exposed to estrogen become feminized, producing egg protein normally synthesized by females. In female fish, estrogen often retards normal sexual maturation, including egg production (Hogan, 2008). Therefore, expired pesticide formulations must be disposed carefully and care should be taken to avoid their discharge to water bodies and thus prevent loss to fish.

\section{CONCLUSIONS}

From the above investigation, we conclude that some of the pesticide formulations (mentioned in results section) were more toxic after shelf life expiry and some remained toxic but there may be variation exists when compared with fresh respective formulation. Based on the observed $\mathrm{LC}_{50}$ values in the study, EC formulation may cause more toxicity in expired condition rather than other type of formulation like WP, SC because of impurities. $\mathrm{pH}$ alteration was found in Dichlorvos 76\% EC, Fenvalerate 20\% EC, Lambda-cyhalothrin 5\% EC, Pretilachlor 50\% EC, Tebuconazole 25\% EC, Hexaconazole 5\% EC and Captan $70 \%+$ Hexaconazole 5\% WP. The altered $\mathrm{pH}$ may cause by-product formation in expired pesticide which lead to acute toxicity to Labeo rohita in the present study. This indicates that there is a requirement of detailed investigation on characterization of the expired pesticides and we suggest that the proper disposal of expired chemical without impairing the aquatic environment is required.

\section{ACKNOWLEDGEMENT}

The authors are thankful to the Management of IIBAT for providing the facility, Dr. A. Ramesh for his kind support and also thank Mrs. P. Aruna Surekha for her support in every phase of this research and Mr. A. Goparaju for statistical analysis of the data.

\section{REFERENCES}

Allan, L., 2000. Fish kills in New South Wales. Department of Agriculture Advisory Note No 4/86. NSW Department of Primary Industries.Available at: http://www.dpi.nsw.gov.au/_data/assets/ pdf_file/0006/202794/nsw-fish-kill.pdf

Ambrus, A., D. J. Hamilton, H. A. Kuiper and K. D. Racke, 2003. Significance of Impurities in the safety evaluation of crop protection products (IUPAC Technical Report), Pure Appl. Chem., Vol. 75 (7): 937- 973. 
APHA, AWWA and WPCF, 1975. Standard Methods for the Examination of Water and Wastewater, 14th ed., Washington D.C.

Blankespoor, B., D. Susmita, D. Walid, L. Abdelaziz, M. Craig, and B.S. Hassine, 2009. Stockpiles of Obsolete Pesticides: Threats to Ecosystems and Biodiversity, Energy and Environment Research, World Bank, Washington, DC.

British crop protection council (BCPC), 2003. The pesticide manual, thirteenth edition (Eds C D S Tomlin).

Burdick, G. E., E. J. Harris, H. J. Dean, T. M. Walker, J. Shea and D. Colby, 1967. The accumulation of DDT in Lake Trout and the effect on reproduction. Trans Amer Fish Soc, 93: 127-136.

David, P., 2005. Environmental and Economic Costs of the Application of Pesticides Primarily in the United States, Environment, Development and Sustainability 7: 229-252.

Don, W. R., B. B. David, K. Balu and N. Henry, 1994. Pesticides in Surface and Ground Water, Council for Agricultural Science and Technology (CAST), Issue paper No. 2, USA.

Dube, P. N., B. B. Hosetti, 2010. Behaviour surveillance and oxygen consumption in the freshwater fish Labeo rohita (hamilton) exposed to sodium cyanide, Biotechnology in Animal Husbandry, 26 (1-2) ; p. 91-103.

FAO, 1995. Prevention of accumulation of obsolete pesticide stocks provisional guidelines, FAO pesticide disposal series 2, The Problem of Obsolete Pesticides, Food and agriculture organization of United Nations, Rome, Italy. p. 3-7. Available at: ftp://ftp.fao.org/docrep/fao/009/v7460e/v7460e.pdf

FAO and DINA, 2004. Pesticide elimination unusable and/or obsolete for the farming company of Muziva In Nicoadala province of Zambézia, Mozambique, Project UTF/MOZ/073/MOZ.

Great, C. P. and J. M. Mehrle, 1969. Decontamination of pesticides in soil. Residue Rev. 29, 137.

Helena, M. and S. Zdenka, 2009. Incidence of animal poisoning cases in the Czech Republic: current situation. Interdisc Toxicol. Vol. 2(2): 48-51.

Hogan, D., 2008. Fish devastated by sex-changing chemicals in municipal wastewater. Science Daily, Feb 20, 2008. Available at: http://www.sciencedaily.com/releases/2008/02/080216095726.htm

Jayashree, N., 2010. Are pesticides turning into poison spray?. Times of India, Sep 17, 2010. Available at: http://timesofindia.indiatimes.com/home/environment/pollution/Are-pesticides-turning-intopoison-spray/articleshow/6569529.cms

K CT, 2009. Disposal of household pharmaceutical waste. Knox County Government. Available at: http://www.knoxcounty.org/health/pharmaceutical_waste.php

Khooharo, A. A., 2008. A study of public and private sector pesticide extension and marketing services for cotton crop. PhD thesis submitted to Sindh Agriculture University, Tando Jam, Sindh, Pakistan.

Khwaja, A. M., M. R. Jan and K. Gul, 2006. Physical verification and study of contamination of soil and Water in and surrounding areas of abandoned persistent Organic pollutant (DDT) factory in North West Frontier Province (NWFP) Pakistan International POPS Elimination Project (IPEP), South Asia.

Kreisberg, J., 2007. Green Pharmacy - Proper medicine disposal protects the environment. Integrative Medicine, Vol. 6(4).

Kreisler, E. and R. Heiss, 2008. Managing expired pesticides as hazardous waste across borders. The Eighth International Conference on Environmental Compliance and Enforcement, Washington, DC.

Mathur, S.M. and J.K. Singh, 2006. Chemical spraying in agriculture and its environmental impact. All India seminar on environmental Impact assessment. The Institution of Engineers (I), Udaipur.

Mavura, W.J. and P.T. Wangila, 2004. Distribution of pesticide residues in various lake matrices: water, sediment, fish and algae, the case of lake Nakuru, Kenya. The African Network For Chemical Analysis of Pesticides, Inaugural Conference Proceedings, Arusha International Conference Centre, Arusha - Tanzania. 
Mike, W., 2007. How to prevent pesticide related fish kills. In: Bulletin 10. Clemson University, Department of Pesticide Regulation, Pendleton. Available at: http://www.clemson.edu/public/ regulatory/pesticide_regulation/bulletins/bulletin_10_how_to_prevent_pesticide_related_fish_kills.pdf

Mwandia, A. and E. Touni, 2006. Obsolete pesticides in Africa - raising awareness of social and environmental implications. Article presented at the International Conference on Pesticide Use in Developing Countries: Environmental Fate, Effects and Public Health Implications.

Napier, G. M., P. G. Fairweather and A. C. Scott, 1998. Records of fish kills in inland waters of NSW and Queensland in relation to cotton pesticides. Wetlands (Australia) 17 (2):60-71.

OECD, 1992. OECD Guidelines for Testing of Chemicals (No.203; Adopted: 17th July, 1992).

OECD-FAO-UNEP, 2000. Pesticide disposal and survey project In Punjab province, Pakistan. OECD-FAOUNEP Workshop on Obsolete Pesticides, Virginia.

Oulmi, Y., R.D.Negele, T. Braunbeck, 1995. Segment specificity of the cythological response in rainbow trout (Oncorhncus mykiss) renal tubules following prolonged exposure to sublethal concentrations of atrazine. Ecotoxicology and Environmental Safety, 32(1):39-50.

PAN , 2007. Strategic Assessment of the Status of POPs Pesticides Trading in South Western Nigeria, Nigeria - Anglophone Africa. Pesticides Action Network, Nigeria.

PAN UK, 1998. Disposal of obsolete pesticides, PMN No. 3, UK. Available at: http://www.panuk.org/archive/Internat/IPMinDC/pmn3.pdf

Paul, S., 2005. Kenya POPs Situation Report: DDT, Pesticides and Polychlorinated Biphenyls. The International POPs Elimination Project (IPEP), Physicians for Social Responsibility (PSR), Kenya.

Rainer, F., E. Capuli, C. Garilao and D. Pauly, 2005. Labeo rohita in fish base. Available at: http://www. fishbase.org/summary/SpeciesSummary. php?genusname=Labeo\&speciesname=rohita

Ram, C. S., 2002. Obsolete pesticides stockpiles in Nepal and its environmental impact. Forum for Protection of Public Interest (Pro Public), Kathmandu, Nepal

SCBWMI, 2005. Discussion paper on pharmaceutical disposal to sewer systems. Available at: http://www.scbwmi.org/PDFs/WMI_Pharm_White_Paper_FinalMarch05.pdf

Shah, B. P. and B. Devkota, 2009. Obsolete pesticides: their environmental and human health hazards. The Journal of Agriculture and Environment, 10: 60-66.

Surendra, K. Y., 2010. Pesticide applications - threat to ecosystems. J. Hum. Ecol., 32(1): 37-45.

West, Inc. and D. Gulley, 1996. TOXSTAT Version 3.5. Univ. of Wyoming, WY, USA. 